\title{
Reflectance properties analysis of mineral based mortars for renders: Research of their energy performance
}

\author{
M.M. Barbero-Barrera ${ }^{\mathrm{a}, *}$, J. Campos-Acosta ${ }^{\mathrm{b}}$, F.J. Neila-González ${ }^{\mathrm{c}}$ \\ a Department of Construction and Technologies in Architecture, Escuela Técnica Superior de Arquitectura, Polytechnic University of Madrid, Avenida Juan \\ de Herrera, 4, 28004 Madrid, Spain \\ b Instituto de Óptica “Daza de Valdés”, Consejo Superior de Investigaciones Científicas, Spain \\ ${ }^{\mathrm{c}}$ Department of Construction and Technologies in Architecture, Escuela Técnica Superior de Arquitectura, Polytechnic University of Madrid, Spain
}

\section{A R T I C L E I N F O}

\section{Article history:}

Received 30 August 2013

Received in revised form 24 February 2014

Accepted 9 March 2014

Available online 24 March 2014

\section{Keywords:}

Façade

Render

Lime

Reflectance

Radiative

Energy

\begin{abstract}
A B S T R A C T
Passive performance of buildings is nowadays one of the key points, not only for reducing energy consumption of buildings, but also for decreasing "fuel poverty". Among the constructive systems in buildings, façades are the ones having higher influence on thermal performance in urban spaces. Lime renders are specialized systems which can improve not only the durability of the support but also the thermal properties. According to previous researches, a modification of their radiative properties can reduce thermal fluxes between $24 \%$ and $89 \%$.

In this paper, the influences of the aggregate content in lime pastes, as well as the nature of the aggregates, colour and roughness, on the visible near and medium infrared reflectance are analyzed. Ten types of aerial lime mortars were prepared and two methods of reflectance determination were performed. Finally, the effect of the resulted reflectance on the constructive systems of façades was analyzed using pseudotime-dependent software, for which an annulation of the thermal fluxes or significant reduction of them can be observed, when modifying the aggregate nature.
\end{abstract}

(ㄷ) 2014 Elsevier B.V. All rights reserved.

\section{Introduction}

According to the International Energy Agency, the building sector is responsible for around $36 \%$ of the final energy consumption [1], which is mainly due to an energy-inefficient envelope followed by an intensive use of energy for conditioning [2]. In spite of the governmental efforts to improve the conditioning equipment of buildings in Spain (2005), 3.4\% and 9.1\% of the households cannot afford the electricity and gas-water bills, respectively $[3,4]$. Nowadays, "fuel poverty" is even more dramatic due to the economic crisis. Under these circumstances, energy efficiency strategies need to be considered; firstly, the constructive system performance and its adaptation to climate in order to achieve thermal comfort with the minimum energy consumption is to be analyzed, and, afterwards, the active systems effectiveness should also be taken into account $[2,5]$.

In urban spaces, external and internal façades (courtyards or dividing walls) are the constructive system with the highest

\footnotetext{
* Corresponding author. Tel.: +34 913364410; fax: +34 913366560.

E-mail addresses: mar.barbero@upm.es (M.M. Barbero-Barrera), Joaquin.campos@csic.es (J. Campos-Acosta),fj.neila@upm.es (F.J. Neila-González).
}

incidence on the energy demand [2]. For this reason, since the energy crisis of the 1970s, different materials and systems have been implemented to improve the thermal resistance of this constructive system, based on the conductive mechanism of thermal transmission. However, radiative properties have scarcely been analyzed, even though thermal fluxes can be reduced between $24 \%$ and $89 \%$ by modifying the radiative properties of the finishing element [6].

Moreover, $98 \%$ of the extraterrestrial solar energy is concentrated within 280 and $3000 \mathrm{~nm}$ [7] divided into $46 \%$ within $378-760 \mathrm{~nm}$, and $29 \%$ and $15 \%$ in $762-1300 \mathrm{~nm}$ and $1305-2500 \mathrm{~nm}$, respectively [8]. Hence, it is clear that a modification in the $378-760 \mathrm{~nm}$ as well as $762-2500 \mathrm{~nm}$ can considerably modify the performance of the surfaces. From those wavelengths onward, most of the energy is mainly absorbed by the water vapour and the carbon dioxide, while under $280 \mathrm{~nm}$, the energy is absorbed by the ozone.

Concerning this, renders are commonly used as protection for the supports to guarantee structural stability as well as to adapt the building to the artistic aesthetic styles. Therefore, a thorough analysis of them is interesting from the energy point of view. In spite of the importance of this issue, the only publication related to renders is the one from Kolokotsa et al. [9] who, in 2012, published 
Table 1

Naming of the mixtures.

\begin{tabular}{|c|c|c|c|c|c|}
\hline & Reference marble dust & Non-coloured microsilica 1 & Non-coloured microsilica 2 & Coloured microsilica 1 & Coloured microsilica 2 \\
\hline $1: 1$ & $\mathrm{R} 1$ & $\mathrm{~A} 1$ & B1 & $\mathrm{C} 1$ & D1 \\
\hline $1: 3$ & $\mathrm{R} 2$ & A2 & B2 & $\mathrm{C} 2$ & D2 \\
\hline
\end{tabular}

a paper analysing the optical performance of several types of mortars applied over a brick support. In addition, reflectance of the Portland cement concrete was examined by Levinson and Akbari [10] and performed in 2010 with the publication of a prototype of a reflective floor tile [11]. In relation to the previous studies, some researches focused on the performance of the coatings [12,13]. The effect of coatings in social housing in summertime was simulated by Santamouris et al. [14]. However, the majority of materials and constructive systems were used to be placed on the roof and pavement [15-21].

In this paper, the influence of the aggregate content in lime pastes as well as the nature of the aggregates, colour and roughness on the visible, near and medium infrared reflectance are researched. Ten types of aerial lime mortars were prepared and two methods of reflectance determination were performed, namely, an experimental one based on the use of a pyranometer and a standard one with a spectrometer. Materials and methods were contrasted and some recommendations on their use have been extracted. Finally, the effect of the resulting reflectance on façades constructive systems has been analyzed using a pseudotime-dependent software.

\section{Materials and methods}

\subsection{Materials}

Following the general criteria "grease over lean", the traditional finishing layer of the renders is commonly made of a blend of fine aggregate and aerial lime [22]. A dolomitic marble dust is the most common aggregate used in Spain. Hence, a mortar comprised by this aggregate and an aerial hydrated lime CL90S, in a proportion ratio $1: 1$, in volume, was used as reference. In addition, the effect of the aggregate content was analyzed by the selection of a high proportion ratio $1: 3$, in volume - one commonly used as base layer. Table 1 shows the names of the mixtures.

The effect of the aggregate nature was evaluated by the substitution of the reference dolomitic marble dust for two types of coloured microsilica dust, which were selected to avoid the "optical roughness" effect [23]. At the same time, colour influence was evaluated by the selection of other two types of ochre-pinkish coloured microsilica dust. Fig. 1 shows the appearance of the mixtures.

Mixtures were poured into $110 \mathrm{~mm} \times 110 \mathrm{~mm}$ moulds of $10 \mathrm{~mm}$ thickness to simulate a render or plaster. Then they were compacted according to UNE EN 196-1. After 7 days of curing time, the samples were demoulded and stored under laboratory conditions $\left(60 \% \mathrm{RH}\right.$ and $\left.20^{\circ} \mathrm{C}\right)$ for 90 days to ensure the stabilization of the mineralogical properties. At this curing time, samples were mechanically smoothed and treated with sandpapers of 40,60 and 100 grit sizes. This was done to examine the effect of roughness on the measurements. Afterwards, specimens were dried at $40 \pm 5^{\circ} \mathrm{C}$ during 7 days and introduced into a desiccator in order to achieve the laboratory temperature and later placed into sealed bags, where they were preserved up to the test day.

\subsection{Methods}

Reflectance measurements were performed by two methods: a standard one based on the use of a spectrophotometer [24], and, alternatively, a portable pyranometer was used to compare the resulted data, because of its higher availability compared to the previous one.

\subsubsection{Portable pyranometer}

The portable pyranometer used was a LICOR 189. This instrument measures the integrated total irradiation, independently from the incidence angle, within the $300-1100 \mathrm{~nm}$ wavelength range. It is equipped with a photovoltaic detector and, although its response does not cover the complete spectral range as thermopile ones do, its price and simplicity are some of the advantages taken into account for using it [25]. The procedure consisted on comparing the irradiance measurements when placed looking at the sky and facing down, with a 3 s difference between them; this implies not paying attention to temporal drift of irradiation. The device was calibrated every ten measures. However, in spite of it, under natural lighting conditions, a total error of $\pm 5 \%$ is implied according to the manufacturer specifications, for which the typical absolute error is of $3 \%$ in the range of environmental temperatures from $15^{\circ} \mathrm{C}$ to $35^{\circ} \mathrm{C}$, as well as the cosine effect [26]. This value is in accordance with similar devices [25,26].

Tests were performed in June 2009 and 2010. Selection of the days and hours was based on the maximum height of the sun with the minimum variation of the type of radiation: direct-diffuse, although variability of the sun and its effect on the measurements was controlled by performing the test in a north room with diffuse radiation towards the sun, following Akbari et al. recommendations

\begin{tabular}{|c|c|c|c|c|c|}
\hline & $\begin{array}{l}\text { Reference } \\
\text { marble dust }\end{array}$ & $\begin{array}{l}\text { Non-coloured } \\
\text { Microsilica } 1\end{array}$ & $\begin{array}{l}\text { Non-coloured } \\
\text { Microsilica } 2\end{array}$ & $\begin{array}{c}\text { Coloured } \\
\text { Microsilica } 1\end{array}$ & $\begin{array}{c}\text { Coloured } \\
\text { Microsilica } 2\end{array}$ \\
\hline \multicolumn{6}{|l|}{$1: 1$} \\
\hline \multicolumn{6}{|l|}{$1: 3$} \\
\hline & & & & & \\
\hline & & & & & \\
\hline & & & & & \\
\hline
\end{tabular}

Fig. 1. Photographs of the mixtures. 
[27]. For each sample, an average of twenty values were registered, with deviations smaller than $1 \%$.

\subsubsection{Spectrophotometer}

A UV/VIS/NIR Spectrophometer, Perkin Elmer Lambda 900, with an integrating sphere of $150 \mathrm{~mm}$ in diameter coated with a barium sulfate paint was used. Reflectance was determined within the $250-2500 \mathrm{~nm}$ wavelength interval, with a gap of $10 \mathrm{~nm}$. The equipment comprises a photomultiplier detector for the ultraviolet and visible ranges and a lead sulphide one for infrared. Deuterium and tungsten lamps were used for ultraviolet as well as visible and near-infrared range, respectively. The equipment consists of a two beam spectrophotometer, but the samples and the reference standard were measured at the same port of the integrating sphere. A geometry $0^{\circ}$ : $\mathrm{d}$ was selected, which means that the incident light is normal to the sample, whereas the reflectance is measured in a diffused way. This selection was chosen because normal position of the incident light is the most unfavourable circumstance for which the highest amount of energy can be absorbed. The main drawback is that the perpendicular illumination of the total surface, included valleys and crests, make grooves not to have a huge influence on the results. In fact, since specular component was included in the measurement, the actual incidence angle was $8^{\circ}$ instead of $0^{\circ}$.

Three measurements were taken for each sample. The reference standard was a spectralon piece referred as CD-07. A zero reflectance reading was taken using a light trap [28] designed and built at the Instituto de Optica. To evaluate the influence of the roughness, sample measurements were taken at different orientations, rotating the sample. Finally, spectral curves were smoothed with Microcal Origin software.

\subsubsection{Simulation in time-dependent state}

Simulations of the thermal performance of four types of constructive systems of façades, in pseudotime-dependent state, were performed by Antesol V.6 software developed by Dr. Manuel Martín Monroy [29]. This software gave us the pseudotime-dependent performance of the constructive system, since the temperature inside had to be fixed (in our case at $20^{\circ} \mathrm{C}$ in winter time and $23^{\circ} \mathrm{C}$ in summer time). The analyzed constructive systems are two characteristics types characteristic of Madrid's historical centre: a brick masonry wall $40 \mathrm{~cm}$ thick and a timber frame (30\% wood and $70 \%$ brick) $20 \mathrm{~cm}$ thick, both of them with a lime render and gypsum plaster. Meanwhile, the other constructive system was common in 50-60s decades: a perforated brick masonry wall $24 \mathrm{~cm}$ thick with gypsum plaster, and a compound wall $(24 \mathrm{~cm}$ of perforated brick, a wall cavity of $5 \mathrm{~cm}$, a panelling with $4 \mathrm{~cm}$ hollow brick and gypsum plaster). Thermal resistance were $0.64,0.59,0.72$ and $0.70 \mathrm{~m}^{2} \mathrm{~K} / \mathrm{W}$, respectively.

For the analysis, south orientation façades with a roughness of 0.40 and an emissivity of 0.90 was stated. Outdoor absorptivity was adjusted to the test results while indoor one was established at 0.3 . As the buildings were placed in an urban area, albedo was fixed at 0.2. Furthermore, climatic data was provided by the Agencia Estatal de Meteorología for Madrid-Retiro station [30]. Solar factor was assumed to be 0.8 in sunny days and 0.1 in cloudy ones. Finally, outdoor and indoor wind speed were $3 \mathrm{~m} / \mathrm{s}$ [31] and $0.2 \mathrm{~m} / \mathrm{s}$ [32], respectively.

\section{Results and discussion}

\subsection{Portable pyranometer}

Reflectances varied between $70 \%$ and $80 \%$ (Graphic 1). Samples $\mathrm{A} 1$ and $\mathrm{B} 1$ with proportion ratio 1:1 showed the highest values, and on the opposite side, samples with R2 and C2 could be found. Hence, in general, the use of micro-silica sand improved the reflectance of the mortars between $5 \%$ and $9 \%$, with the exception of the $\mathrm{C} 2$ mixture which could be due to its dark ochre-pinkish colour.

Given that the equipment registered the reflectance in a spectrum $(300-1100 \mathrm{~nm})$ in which visible range $(380-760 \mathrm{~nm})$ has significant influence, white materials showed the highest reflectance. And, for the same reason, white microsilica mortars showed a slightly higher reflectance $(0.2-1.3 \%)$ than the coloured ones.

\subsection{Spectrophotometer}

With the spectrophotometer (Graphic 2), average reflectances were within $72 \%$ and $93 \%$, which means that they are slightly higher than those measured with the pyranometer. This implies that samples reflect higher amount of energy when it is directional rather than in a diffused way. It is important to notice that since in summertime most of the energy comes in a direct way, consequently, a rejection of solar gains increases.

Regarding roughness, differences were lower than $2 \%$ in all cases except for the R1 and B2. In these cases, reflectance increased for rough samples while the opposite took place in the micro-silica ones due to the differences in the particle size. According to Howell and Siegel, optical roughness depends on the relation between the "root-mean-square" and the wavelength [23]. It implies that, in both cases, roughness has a significant influence on the directional reflectance (their values were over the unit, namely, 12-37

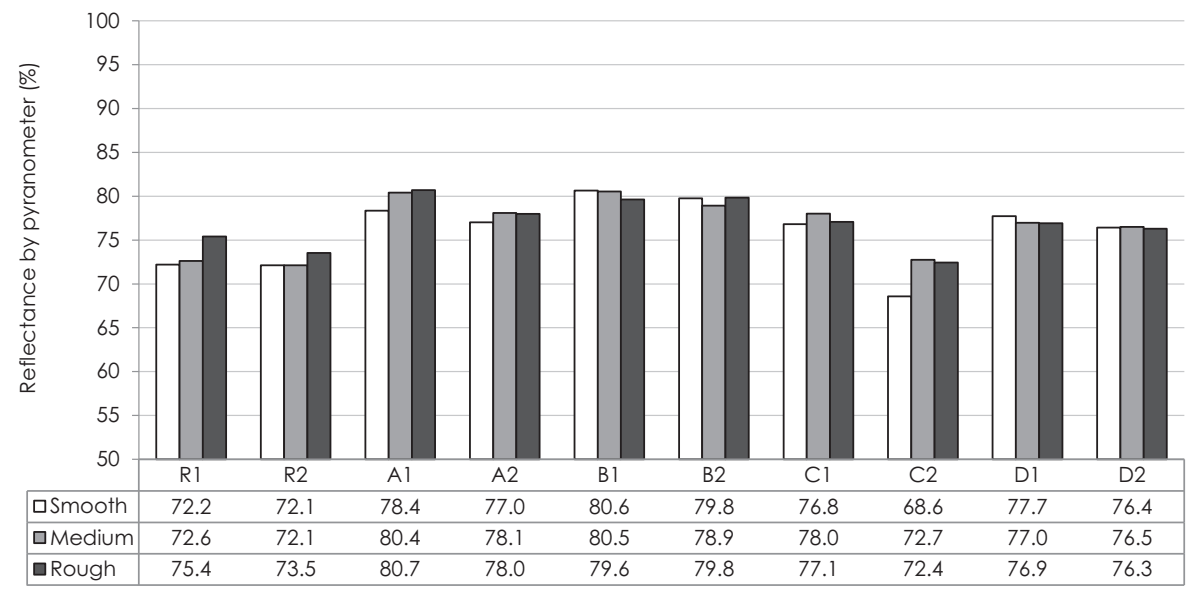

Graphic 1. Pyranometer reflectance as finishing function, in percentage. 


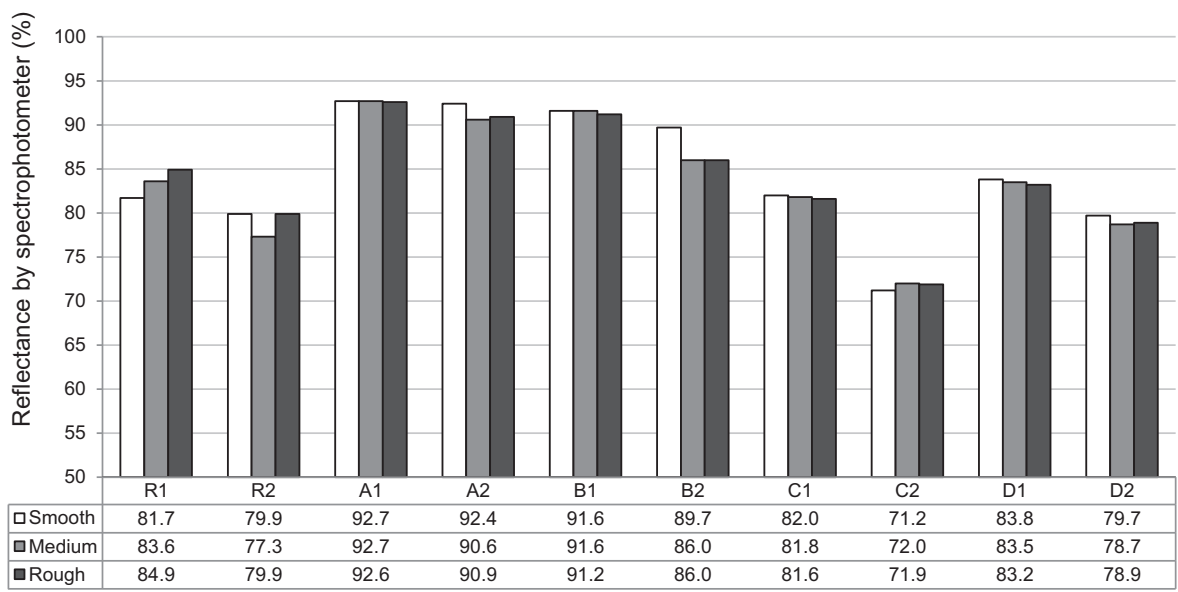

Graphic 2. Reflectance at $300-1100 \mathrm{~nm}$, by spectrophotometer.

in microsilica samples and 90-263 in dolomitic ones). However, it is clear that incident radiation is not trapped in the irregularities of the dolomitic mortars, whereas the opposite took place in the microsilica ones.

On the other hand, once again, at $300-1100 \mathrm{~nm}$, the highest reflectance values were achieved by the white samples compared to the coloured ones, as was expected in the visible spectrum. This is also the reason why differences between both methods were less marked in the coloured samples (Graphic 3).

At the same time, it should be taken into account that, while pyranometer gives weighed values for the spectral distribution of daylight, the same weight is given for all the wavelengths in the case of the spectrometer by integral values. This is important since, in the cases in which samples reflectance on the near infrared would be higher than in the visible range, reflectance with the pyranometer would be lower. The reason for that is that daylight has a lower content of power in the near infrared than in the visible. This explains the low reflectance showed by the $\mathrm{C} 2$ samples because, as can be observed in Graphic 4, their reflectance in the visible range $(380-760 \mathrm{~nm})$ is low compared to the rest of the spectrum. Furthermore, in this Graphic 2, it is also clear that, in general, micro-silica samples reflect a higher amount of energy in the infrared spectrum than the dolomitic ones.

However, taking into account that $44 \%$ of the solar power is received ranging from $770 \mathrm{~nm}$ to $2500 \mathrm{~nm}$, compared to the $46 \%$ of the visible range $(380-760 \mathrm{~nm})$, the former acquires a huge importance from an energy point of view since, the dazzle effect is avoided. Hence, if we compare the reflectance in the pyranometer wavelengths (300-1100 $\mathrm{nm})$ and the total $(300-3000 \mathrm{~nm})$ as well as the medium infrared (770-2500 nm) intervals (Graphic 5), both have a notable effect, especially in coloured samples. In these ones, the highest reflectance corresponds to the medium infrared interval followed by the total reflectance or the visible one. The amount of coloured aggregate determines its influence on the reflectance. When they increase (proportion ratio 1:3), the total reflectance is higher than the visible reflectance, whereas the opposite takes place in the mixing ratios with higher amount of binder (namely, $1: 1)$ due to the influence of the latter.

Since the higher the chromaticity of colours, the higher the differences between reflectances in different intervals, the use of the pyranometer as technique for relative reflectance measurements can be considered, in these type of materials, only in the case of samples with similar colour and lightness. Furthermore, reflectance would be lower for white colours and almost similar for coloured ones (Graphic 3) when compared to the standard method.

Taking into account the total spectrum (300-2500 nm), A1 and B1 (white micro-silica samples) increased the reflectance in 21\% compared to R1, while A2 and B2 increased 15\% compared to R2. Moreover, the use of coloured micro-silica aggregate also improves the reflectance compared to the reference samples, in $14 \%$ and $2 \%$ in the mixing ratios $1: 1$ and $1: 3$, respectively. The darker colour of the latter $(1: 3)$ is the reason for this reduction in the reflectance.

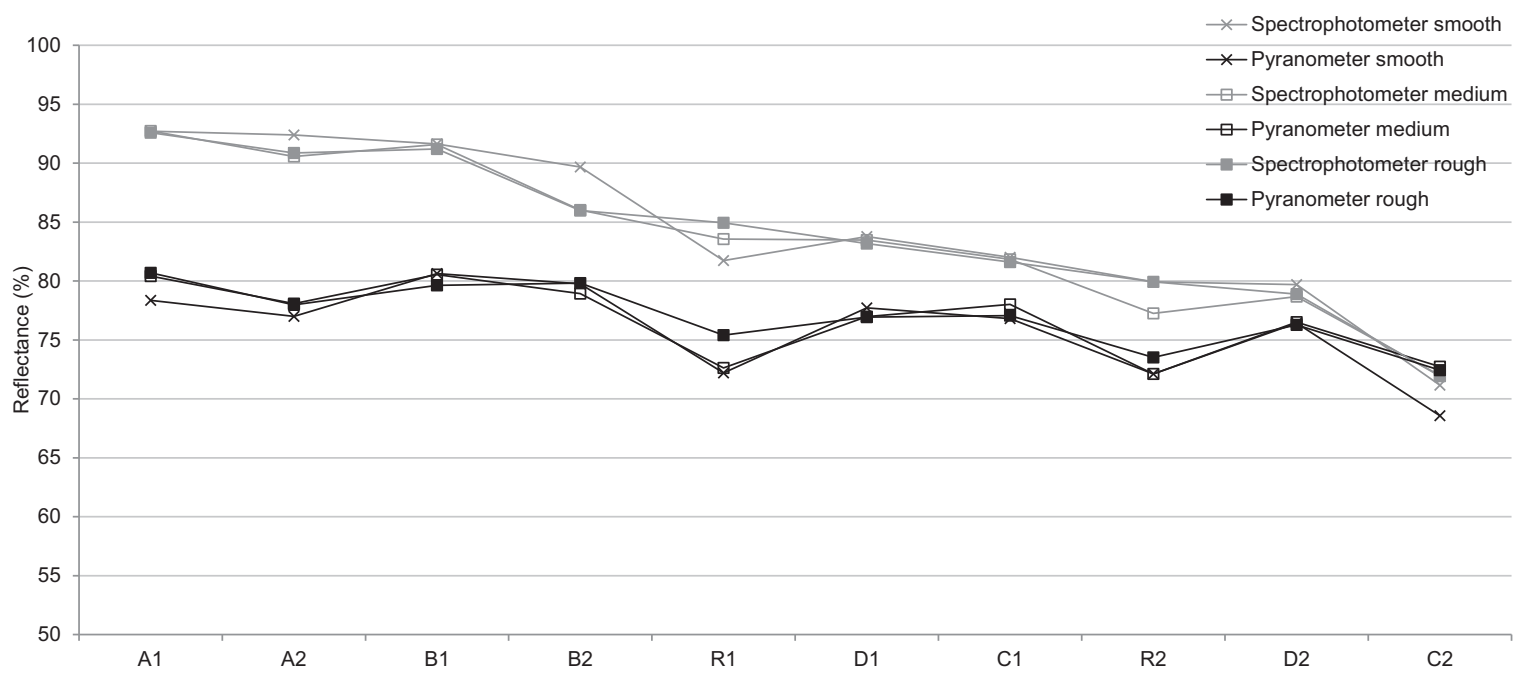

Graphic 3. Reflectance at 300-1100 nm, by spectrophotometer (grey) and pyranometer (black). 

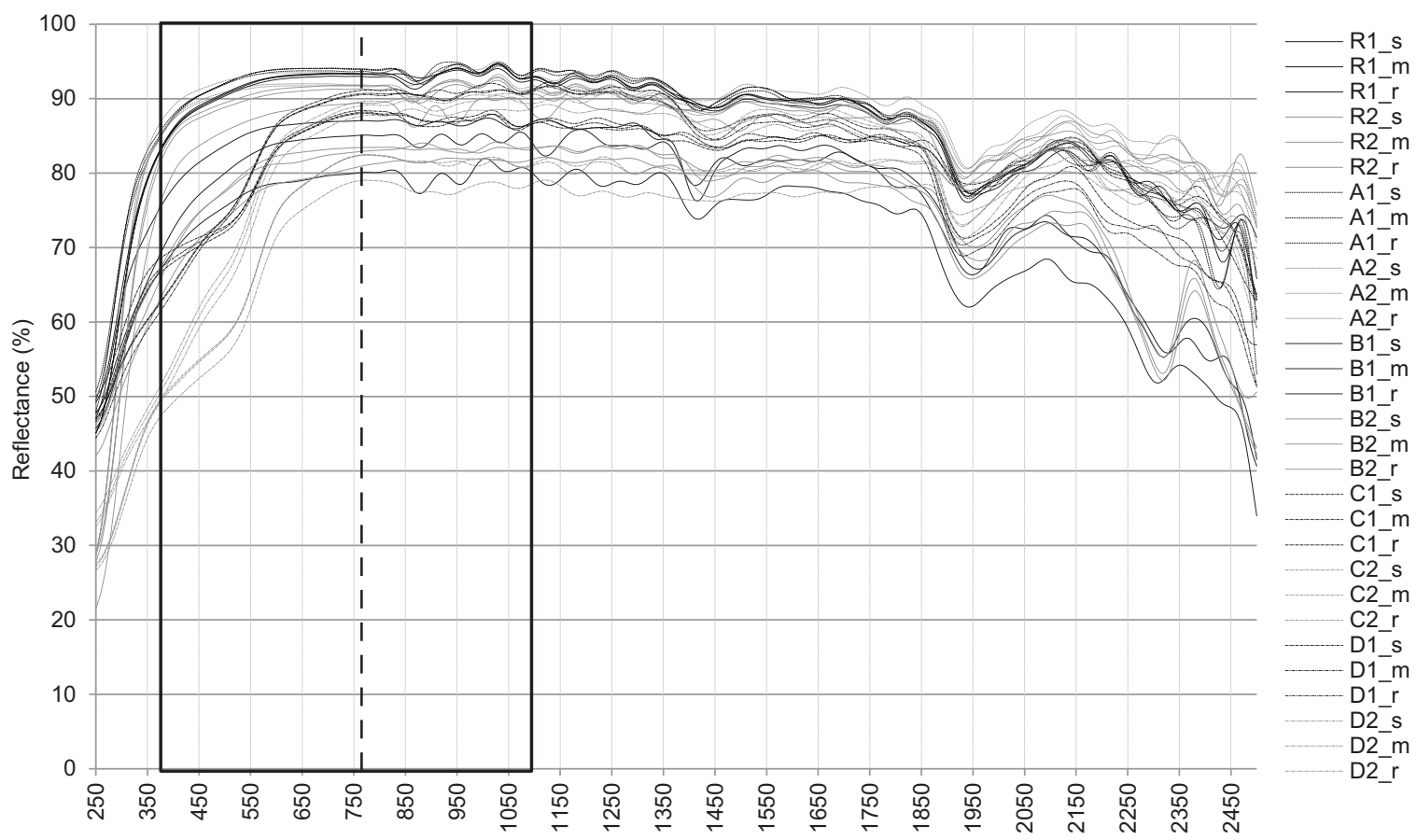

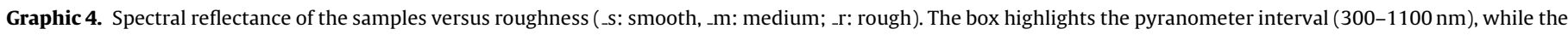
dashed line marks the limit of the visible range and the infrared one.

For the aforementioned, it is foreseeable that, in summertime, substitution of the dolomitic dust by the microsilica notably enlarges the reflectance, which implies a reduction on the thermal fluxes in the building as well as an improvement of its energy efficiency.

\subsection{Simulation in time-dependent state}

As expected, strategies are controversial depending on the season (Graphic 6). In wintertime conditions, thermal fluxes increase with the reduction of the absorptivity, because of the decrease of solar gain compensating thermal losses. Differences achieve $32-33 \%$ in clear days and $6-7 \%$ in the cloudy ones with the lower values in the reference samples. However, as the inclination of the solar beams is smaller in wintertime, solar radiation in façades placed in urban centres is limited or even null in winter [2]. Under this circumstance, differences in thermal fluxes are limited at $0.2 \mathrm{~W} / \mathrm{m}^{2}$ in all cases. Hence, absorptivity has almost no influence on the results.

In summertime, the reduction of solar gain by a low absorptivity of the surface implies that fluxes become null in clear days or reduce

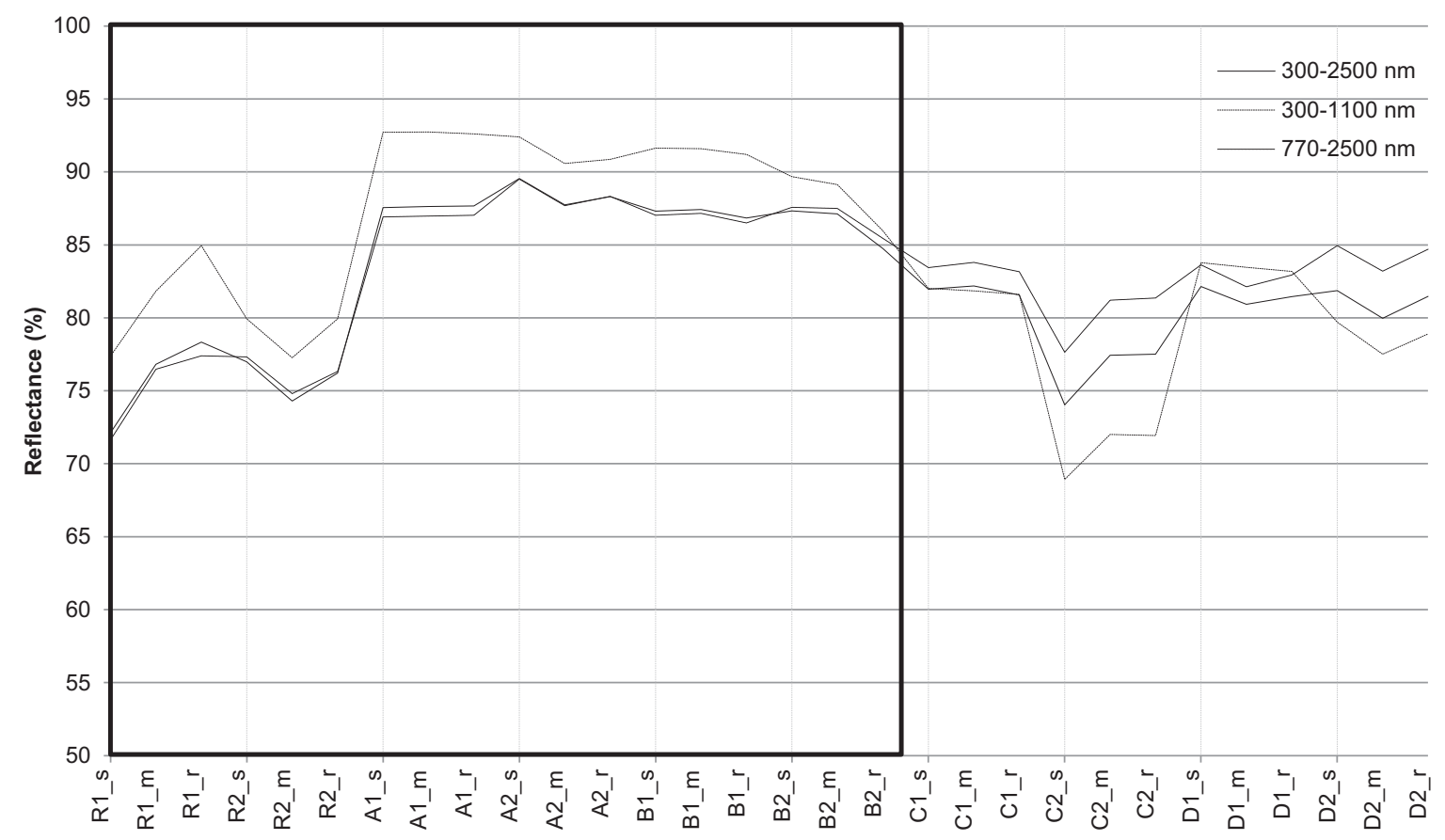

Graphic 5. Reflectance in different wavelength intervals for different finishing (_s: smooth; _m: medium; _r: rough). The box highlights the non-coloured samples. 


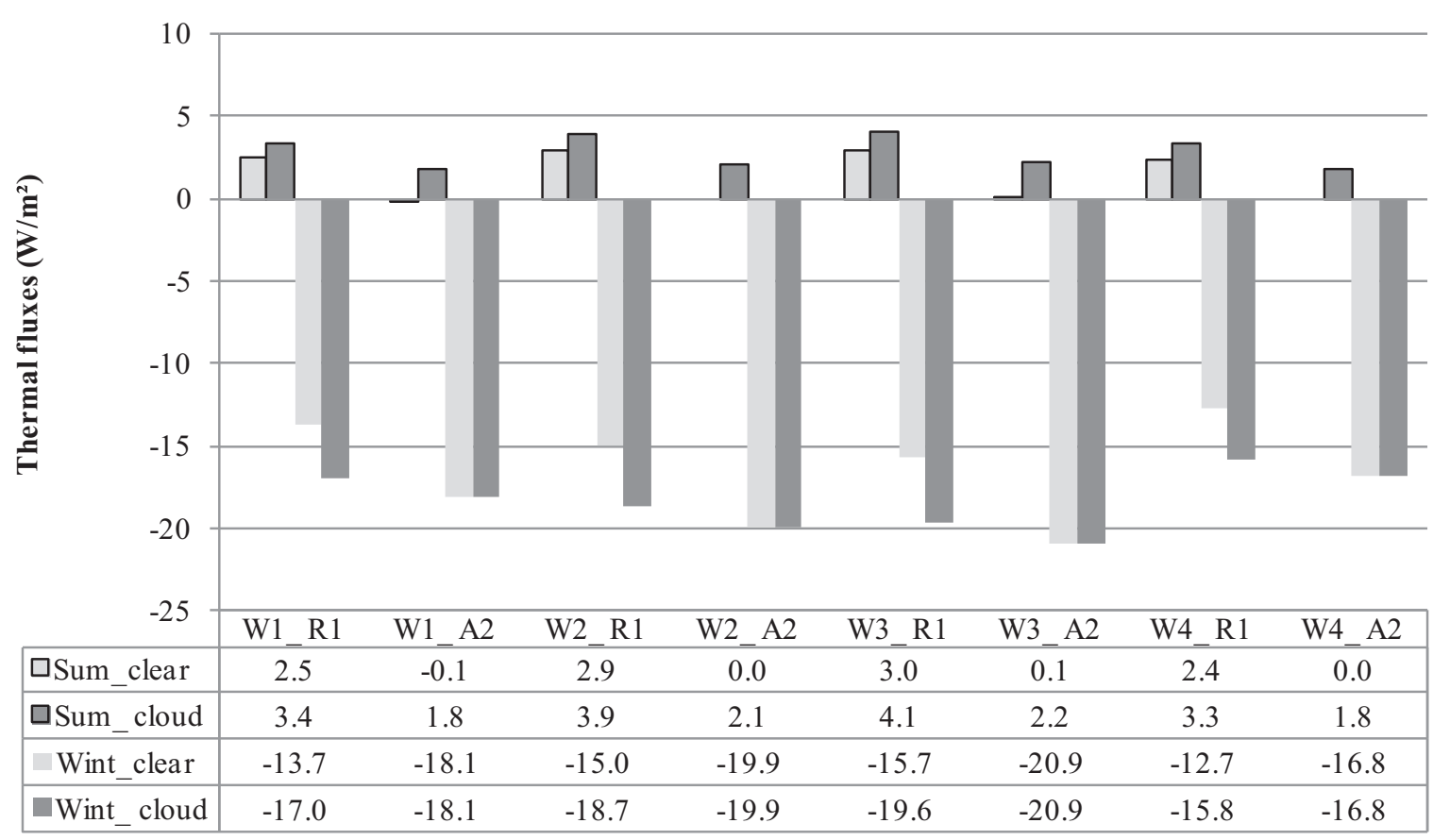

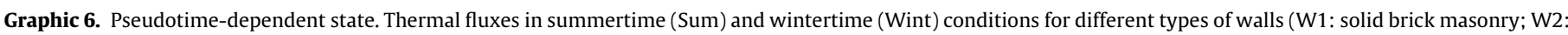
Wooden lattice; W3: perforated brick; W4: compounded wall).

Table 2

Pseudotime-dependent state. Clear/cloudy days (W1: solid brick masonry; W2: Wooden lattice; W3: perforated brick; W4: compounded wall).

\begin{tabular}{llll}
\hline & & Summer $\left(\mathrm{W} / \mathrm{m}^{2}\right)$ & Winter $\left(\mathrm{W} / \mathrm{m}^{2}\right)$ \\
\hline W1 & $\alpha_{\mathrm{sw}}=0.90$ & $11.2 / 9.0$ & $0.8 /-13.3$ \\
W2 & $\alpha_{\mathrm{sw}}=0.90$ & $12.7 / 10.2$ & $1.1 /-14.5$ \\
W3 & $\alpha_{\mathrm{sw}}=0.90$ & $13.4 / 10.7$ & $1.3 /-15.2$ \\
W4 & $\alpha_{\mathrm{sw}}=0.90$ & $10.6 / 8.5$ & $0.7 /-12.3$ \\
\hline
\end{tabular}

1.9 times in cloudy days which implies the best performance of the mortar A2 in comparison to the reference one.

Compared to the previous researches (6) in which thermal fluxes were reduced between $24 \%$ and $89 \%$ for samples of high absorptivity $\left(\alpha_{\mathrm{sw}}=0.90\right)$ and even null ones $\left(\alpha_{\mathrm{sw}}=0.05\right)$, in this case a modest reduction is achieved since absorptivity is 0.28 and 0.11 in $\mathrm{R} 1$ and A2, respectively. In any case, according to Table 2, comparing results with a render of high absorptivity in short wavelength $\left(\alpha_{\mathrm{sw}}=0.90\right)$, the same controversial results can be observed and thermal fluxes are reduced between 2.5 and more than 100 times in summertime conditions. Under this circumstance, the reflectance strategy is confirmed to be suitable in the case a summer approach prevails.

On the other hand, absorptivity of the reference samples are similar to the one found in the bibliography for clear coatings $[9,33,34]$ while microsilica mortars show similar values to some of the analyzed samples by Kolokotsa et al. [9]. In any case, both reference and microsilica mortars show considerably lower absorptivity than common building materials such as concrete [10], ceramics and cement [35] tiles [27,34] or most of pigmented films [36]. This fact confirms the use of coatings $[37,38]$ or renders in walls in order to improve the performance of constructive systems of façade, especially in summertime conditions.

From the aforementioned, in urban spaces with solar obstruction, a reduction of the solar absorptivity should be preferred so as to improve the energy efficiency in summertime. For the same reason, this strategy should be pointed out if the ongoing trend is a widespread increase of temperatures. However, the suitable solution should be in accordance with the climatic conditions, and a thorough analysis of each specific circumstance would be necessary.

\section{Conclusions}

Visible and near infrared reflectance of ten types of lime mortars for renders were analyzed in order to determine the influences of the aggregate nature (dolomitic and four types of microsilica dust), content (1:1 and 1:3, by volume), colour (white and pinkish coloured) and roughness (smooth, medium and rough). Reflectances ranged between $72 \%$ and $93 \%$ which is notably high in comparison to other materials. In addition, substitution of dolomitic dust by microsilica implied an increase of $15-21 \%$ and $2-14 \%$ in the white and pinkish coloured samples, respectively.

This implies that thermal fluxes in summertime become 24-29 times lower in clear days and 1.9 times lower in cloudy days when compared to the use of the reference mortar. Meanwhile, in wintertime, considering urban spaces with solar obstruction, variation of the absorptivity has almost no influence. Compared to the theoretical analysis previously performed, a lower reduction of thermal fluxes has been achieved due to the comparison of materials with a limited difference. However, if we compared them with a material with high absorptivity in shortwavelength, a reduction of thermal fluxes between 2.5 and more than 100 times is found. From this point of view, the use of these types of renders in the constructive systems of façades considerably improves the thermal performance of them compared to common building materials, especially in summertime conditions.

At the same time, a standard method for reflectance determination with a spectrophotometer was compared to an experimental one with a pyranometer in the same wavelength range. According to the results, a pyranometer can be used as relative reflectance measurement when samples of similar colour and brightness are considered. In the case of white samples, differences of $10 \%$ were found between both methods, whereas they reduced up to $3-4 \%$ in the case of the coloured ones. 


\section{References}

[1] IEA, World Energy Outlook 2007, International Energy Agency Publications, France, 2008, Available from: www.worldenergyoutlook.org

[2] M. Luxán García de Diego, M. Vázquez Espí, G. Gómez Muñoz, E. Román López, M.M. Barbero Barrera, Actuaciones con criterios de sostenibilidad en la rehabilitación de viviendas en el centro de Madrid, Empresa Municipal de la Vivienda y Suelo, Madrid, 2009.

[3] P. Nolay (Coord.), Evaluación de la pobreza energética en Bélgica, España, Francia, Italia y Reino Unido. EPEE Project WP2-Deliverable 6, European Commission, France, 2011. Available from: http://www.fuel-poverty.org/files/ WP2_D6_SPANISH.pdf

[4] S. Tirado Herrero, J.L. López Fernández, P. Martín García, Pobreza Energética en España. Potencial de Generación de empleo derivado de la rehabilitación energética de viviendas, Asociación de Ciencias Ambientales, Madrid, 2012.

[5] M.M. Barbero Barrera, G. Gómez Muñoz, E. Román López, La envolvente como elemento fundamental de eficiencia energética y confort en la rehabilitación de edificios de viviendas, El inmobiliario mes a mes Junio/Julio (2012) 24-26.

[6] M.M. Barbero Barrera, F.J. Neila González, L. Maldonado Ramos, A. García Santos, K. Van Balen, Energy renovation by lime renders, in: J. Válek, C. Groot, J.J. Hughes (Eds.), Historic Mortars and RILEM TC 203-RHM Final Workshop HMC 2010, RILEM Publications s.a.r.l., France, 2010, pp. 891-899.

[7] A. Pons Aglio, Diseño e instalación de un sistema experimental de medida de la irradiancia solar. Evaluación y análisis de la irradiancia solar en Madrid, Instituto de óptica "Daza de Valdés” CSIC, Madrid, 1980.

[8] A. Barrio Cuesta, Medida del espectro de Irradiancia Solar. Contribución al estudio de la variación de la eficacia luminosa y su aplicación al aprovechamiento de la luz natural, Universidad de Valladolid, Valladolid, 2000.

[9] D. Kolokotsa, P. Maravelaki-Kalaitzaki, S. Papantoniou, E. Vangeloglou, M. Saliari, T. Karlessi, M. Santamouris, Development and analysis of mineral based coatings for buildings and urban structures, Solar Energy 86 (2012) 1648-1659.

[10] R. Levinson, H. Akbari, Effects of compositions and exposure on the solar reflectance of Portland cement concrete, Cement and Concrete Research 32 (2002) 1679-1698.

[11] R. Levinson, H. Akbari, P. Berdahl, K. Wood, W. Skilton, J. Petersheim, A novel technique for the production of cool colored concrete tile and asphalt shingle roofing products, Solar Energy Materials and Solar Cells 94 (2010) 946-954.

[12] M. Kohl, C. Prager, M. Heck, S. Herkel, Influence of the IR reflection of painted façades on the energy balance of a building, Energy and Buildings 38 (2006) 1369-1379.

[13] A. Synnefa, M. Santamouris, I. Livada, A study of the thermal performance of reflective coatings for the urban environment, Solar Energy 80 (2006) 968-981.

[14] M. Santamouris, K. Pavlou, A. Synnefa, K. Niachou, D. Kolokotsa, Recent progress on passive cooling techniques - advanced technological developments to improve survivability levels in low-income households, Energy and Buildings 39 (2007) 859-866.

[15] H. Akbari, H. Taha, The impact of trees and white surfaces on residential cooling energy use in 4 Canadian cities, Energy 17 (1992) 141-149.

[16] A.H. Rosenfeld, H. Akbari, S. Bretz, B.L. Fishman, D.M. Kurn, D. Sailor, H. Taha, Mitigation of urban heat islands - materials, utility programs, updates, Energy and Buildings 22 (1995) 255-265.

[17] A.H. Rosenfeld, H. Akbari, J.J. Romm, M. Pomerantz, Cool communities: strategies for heat island mitigation and smog reduction, Energy and Buildings 28 (1998) 51-62.

[18] A. Niachou, K. Papakonstantinou, M. Santamouris, A. Tsangrassoulis, G. Mihalakakou, Analysis of the green roof thermal properties and investigation of its energy performance, Energy and Buildings 33 (2001) 719-729.
[19] R. Levinson, H. Akbari, J.C. Reilly, Cooler tile-roofed buildings with nearinfrared reflective non-white coatings, Building and Environment 42 (2007) 2591-2605.

[20] C. Michels, R. Lamberts, S. Güths, Evaluation of heat flux reduction provided by the use of radiant barriers in clay tile roofs, Energy and Buildings 40 (2008) 445-451.

[21] A. Synnefa, T. Karlessi, N. Gaitani, M. Santamouris, D.N. Assimakopoulos, C. Papakatsikas, Experimental testing of cool colored thin layer asphalt and estimation of its potential to improve the urban microclimate, Building and Environment 46 (2011) 38-44.

[22] M.d.M. Barbero-Barrera, L. Maldonado-Ramos, K. Van Balen, A. García-Santos, F.J. Neila-González, Lime render layers: An overview of their properties, Journal of Cultural Heritage (2013), http://dx.doi.org/10.1016/j.culher.2013.07.004 (in press).

[23] R. Siegel, J. Howell, Thermal Radiation Heat Transfer, 4th ed., Taylor \& Francis, USA, 2002

[24] CIE 130, Practical Methods for the Measurement of Reflectance and Transmittance, CIE, France, 1998.

[25] J.A. Duffie, W.A. Beckman, Solar Engineering of Thermal Process, 3rd ed., Wiley \& Sons Inc, USA, 2006.

[26] W.W. Biggs, Principles of Radiation Measurement, LI-COR, USA, 1984.

[27] H. Akbari, R. Levinson, S. Stern, Procedure for measuring the solar reflectance of flat or curved roofing assemblies, Solar Energy 82 (2008) 648-655.

[28] P.A. Van Nijnatten, M.G. Hutchins, N.B. Kilbey, A. Roos, K. Gelin, F. GeottiBianchini, P. Polato, C. Anderson, F. Olive, M. Köhl, R. Spragg, P. Turner, Uncertainties in the determination of thermal emissivity by measurement of reflectance using Fourier transform spectrometers, Thin Solid Films 502 (2006) 164-169.

[29] M. Martín Monroy, Comportamiento térmico de cerramientos soleados: un modelo de simulación por diferencias finitas, Universidad de Las Palmas de Gran Canaria, Las Palmas de Gran Canaria, 1996.

[30] Agencia Estatal de Meterología, Weather Database for Madrid-Retiro, 2013 (accessed June 2013)

[31] Instituto Nacional de Meteorología, Rosas de los vientos del periodo 1971-2000, Subdirección General de Programas Especiales e Investigación Climatológica, Madrid, 2007.

[32] F.J. Neila González, Arquitectura bioclimática en un entorno sostenible, Editorial Munilla Lería, Madrid, 2004.

[33] T. Karlessi, M. Santamouris, K. Apostolakis, A. Synnefa, I. Livada, Development and testing of thermochromic coatings for buildings and urban structures, Solar Energy 83 (2009) 538-551.

[34] M. Santamouris, A. Synnefa, T. Karlessi, Using advanced cool materials in the urban built environment to mitigate heat islands and improve thermal comfort conditions, Solar Energy 85 (2011) 3085-3102.

[35] R.T. Araújo-Prado, F. Lourenço-Ferreira, Measurement of albedo and analysis of its influence the surface temperature of building roof materials, Energy and Buildings 37 (2005) 295-300.

[36] R. Levinson, P. Berdahl, H. Akbari, Solar spectral optical properties of pigments. Part II: Survey of common colorants, Solar Energy Materials and Solar Cells 89 (2005) 351-389.

[37] C. Prager, M. Köhl, M. Heck, S. Herkel, The influence of the IR reflection of painted façades on the energy balance of a building, Energy and Buildings 38 (2006) 1369-1379.

[38] A. Synnefa, M. Santamouris, H. Akbari, Estimating the effect of using cool coatings on energy loads and thermal comfort in residential buildings in various climatic conditions, Energy and Buildings 39 (2007) 1167-1174. 